\title{
An I-P/C Model of Employee-Organization Relationship: A Dual Perspective
}

\author{
(C) Higher Education Press and Springer-Verlag 2010
}

\begin{abstract}
Most existing studies on employee-organization relationship (EOR) are either from the employee perspective (e.g., the psychological contract approach) or from the employer perspective (e.g., the inducement and contribution approach). Drawing upon prior research, we propose in this paper an inducement-performance/commitment (I-P/C) model based on a dual perspective. Our empirical test on the model reveals that developmental inducements have stronger effects on employees' contributions than economic inducements, and that the incongruent perception of inducements between employees and managers moderates the relationship between organizational inducements and employee contributions. We also find that employee satisfaction varies in different I-P/C combination categories.
\end{abstract}

Keywords social exchange theory, employee-organization relationship, perceptual incongruence, job satisfaction

Translated from Keyan Guanli 科研管理 (Science Research Management), 2009, (6): 141-151

Jihong $\mathrm{Wu}(\bowtie)$

Economics and Management School, University of Electronic Science and Technology of China, Chengdu 610054, China

E-mail:wujh@uestc.edu.cn

Weizheng Chen

Business School, Sichuan University, Chengdu 610064, China

E-mail: charleswchen@163.com

Yun Liu

School of Business Administration, Shanghai Lixin University of Commerce, Shanghai 201620, China

E-mail: liuyundevy@163.com 


\section{Introduction}

Employee-organization relationship (EOR) reflects the social exchange between an individual employee and his/her organization (March and Simon, 1958). The relationship involves both employers and employees. Most previous studies on EOR have been done from either employees' perspective (e.g., the psychological contract approach; Rousseau, 1995) or from employers' perspective (e.g., the inducement and contribution approach; Tsui, Pearce, Porter and Tripoli, 1997; Wang, Tsui, Zhang and Ma, 2003).

Psychological contract (PC) is the expectation of reciprocal obligations between employees and organizations (Levinson, Price, Mandl and Solley, 1962; Schein, 1965). Traditionally, psychological contract has been conceptualized unilaterally as an individual employee's beliefs regarding the terms and conditions of a reciprocal exchange agreement between the focal person and the organization (Rousseau, 1989). To date, much research on PC has adopted this unilateral perspective. However, this approach is challenged from time to time because of its negligence of employer's role. For example, when questioning the viewpoint that organizations cannot "perceive," Guest (1998) highlighted the function of managers as organizational agents in the development of EOR.

The other stream of research largely focuses on employers' perspective of EOR to study the organizational inducements and expected employee contributions. For example, Barnard (1938) indicated that employees respond to organizational inducements with their contributions to valued organizational goals. Tsui et al. $(1995,1997)$ viewed EOR as an employer's active management of its relationship with employees in exchange for their contributions. Based on the relative level of inducements offered by organization and contributions that employees are expected to make, they proposed four general employment relationships: quasi spot contract, underinvestment, overinvestment and mutual investment. However, an implicit assumption of this approach is that employees will reciprocate to organizational inducements and it remains relatively unclear whether employees would actually reciprocate or how they reciprocate. Given the fact that EOR is an exchange process involving both employees and employers, EOR research from both perspectives can help provide a more complete picture.

We aim to make three contributions to the literature. First, we employed a dual perspective and collected data from both employers and employees regarding organizational inducement. Recently, some psychological contract researchers have advocated assessing psychological contract from a dual perspective (e.g., Tekleab and Taylor, 2003; Chen, Tsui and Zhong, 2008), as well as examining the reciprocal process (Coyle-Shapiro and Kessler, 2002). On the inducement-contribution side, however, few attempts have been made to enrich 
the domain by including the employees' perspective. The present study fills the gap by employing a dual perspective to explore the social exchange between employees and employers.

Second, employers' perception and employees' perception of organizational inducement may not always be congruent. Following previous studies relating perceptual incongruence on employees' attitudes (Porter, Pearce, Tripoli and Lewis, 1998; Lester, Turnley, Bloodgood and Bolino, 2002; Li and Sun, 2006), we include perceptual incongruence as a moderator for the relationship between inducement and employee performance and commitment.

Lastly, this study assesses the impacts of different states of EOR on employee satisfaction. We categorize our sample into eight groups $(2 \times 2 \times 2)$ according to their relative standings on each of the three main dimensions: inducements offered by the organization, employee performance, and employee commitment. We also test whether employees' satisfaction differs among EOR categories.

\section{Theories and the Model}

Before discussing EOR, it is necessary to clarify what is exchanged between employees and their organizations. According to content analysis in previous studies (Roehling, Cavanaugh, Moynihan and Boswell, 2000; Wu and Chen, 2010), organization's inducements consist of economic and developmental inducements, which is consistent with representative EOR studies from the employer's perspective (Tsui et al., 1997; Wang et al., 2003). Economic inducements refer to compensation in the form of money and fringe benefits, while developmental inducements include employee development practices such as career management, empowerment, and participation in decision-making. Employees' contributions include task performance, organizational citizenship behavior (OCB), and commitment to organization. Task performance refers to "the effectiveness with which job incumbents perform activities that contribute to the organization's technical core either directly by implementing a part of its technological process, or indirectly by providing it with needed materials or services" (Borman and Motowidlo, 1997). OCB is defined as "contributions to the maintenance and enhancement of the social and psychological context that supports task performance" (Organ, 1997), and organizational commitment as "a psychological state that characterizes an employee's relationship with his/her organization, and has implications for the decision to continue or discontinue membership in the organization" (Meyer and Allen, 1991).

Our definition of employees' contributions is slightly different from prior studies in terms of commitment. Some prior studies considered items related to commitment as part of employee obligations in their psychological contract (e.g., Robinson, Kraatz and Rousseau, 1994), but not as a main contribution of 
employees toward their organizations. We argue that organizational commitment can be considered as an important contribution because it also reflects the reciprocation of employees to their organizations (Tetrick et al., 2008). Previous quantitative reviews suggested that the commitment-performance correlation is moderate at best (Riketta, 2002, Meyer, Stanley, Herscovitch and Topolnytsky, 2002), indicating that high performers do not always embrace high commitment to their organizations. When discussing what employees are supposed to contribute towards their organizations, it is better to view performance and commitment as different contributions that employees can make.

\subsection{Effect of Organizational Inducements on Employee's Contributions}

In a social exchange relationship, when one party voluntarily provides benefits to another, it invokes obligations for the other party to reciprocate by providing some benefit in return (Whitener, Brodt, Korsgaard and Werner, 1998). Organizational inducements are also provided to obtain its employees' repayment in return. Norm of reciprocity in social exchange theory can be advanced as an explanatory mechanism for understanding the relationship between organizational inducements and employee contributions.

The norm of reciprocity, in its universal form, makes two interrelated, minimal demands: (1) People should help those who have helped them, and (2) people should not injure those who have helped them (Gouldner, 1960). When one party benefits another, the recipient will feel indebted to the donor, and an obligation of repayment is thus generated. Based on the social exchange theory, positive organizational inducements will lead to employees' indebtedness and increase their performance and commitment to organization.

Some studies provided partial support to the positive correlation between organizational inducements and employee's contributions. For instance, pay for performance or pay for competence, which can be viewed as part of economic inducements, positively affect employee's task performance (Murray and Gerhart, 1998; Greene and Podsakoff, 1978). Compensation, which can be looked as a form of economic inducements, is positively correlated with employees' commitment (Parker and Wright, 2001; Al-Waqfi and Agarwal, 2006; Kuvaas, 2006). Some forms of developmental inducements, like career management (Long, Fang and Ling, 2002) and empowerment (Leana, 1987) are reported to predict task performance positively. Career management (Long et al., 2002), participation in decision-making (Farmer and Fedor, 1997), empowerment (Laschinger and Finegan, 2004), and perception of fairness (McFarlin and Sweeney, 1992) are proved to affect organizational commitment. Employee's overall perception of inducements offered by organization, i.e., perceived organization support, has positive effect on employee's task performance, OCB, 
and organizational commitment (Wayne, Shore, Bommer and Tetrick, 2002).

According to the norm of reciprocity, and based on research findings of the above studies, we propose the following hypothesis:

H1 Organizational inducement is positively related to employee task performance, organizational citizenship behavior, and organizational commitment.

\subsection{Moderating Effect of Incongruent Perception of Inducements}

Though both employees and employers accept norms of reciprocity, they can, and often do, have very different perceptions of mutual obligation and fulfillment of these obligations (Morrison and Robinson, 2004). These different perceptions have been referred to as incongruence (Morrison and Robinson, 1997). The perception gap can be constructed by subtracting the organization representatives' report of inducements from each employee's report of the extent to which an inducement is offered (Porter et al., 1998). A "negative gap" indicates that employees perceive that there are less of the inducements being offered than do the representatives, while a "positive gap" indicates that the employee perceives that more of the inducements are being offered than do the representatives. A few studies proved the existence of incongruent perceptions and its negative effect on employee's attitudes (Porter et al., 1998; Lester et al., 2002).

Although employees intend to under-appreciate the inducements offered by their organization (Kotter, 1973), and overestimate the degree to which organizations betray their psychological contract (Lester et al., 2002), Porter et al. (1998) still found the existence of both "positive gap" and "negative gap." "Negative gap" may lead to feelings of psychological contract violation directly, and "positive gap" can also have risk of making employees disappointed. Therefore either positively or negatively incongruent perception of inducements between supervisors and subordinates is not helpful for efficient social exchange between organizations and employees. Thus we have the following hypothesis.

H2 Incongruent perception of inducements moderates the relationship between organizational inducements and employee's contributions, such that the relationship is stronger when the incongruence is small.

\subsection{EOR Types Based on I-P/C Model and Its Effect on Employees' Satisfaction}

As the current study investigates EOR from a dual perspective at the individual level, on the assumption that organizations may offer different inducements to different employees and employees also perform different levels of performance and commitment, employees' feeling of the exchange state (expressed as 
satisfaction) may be different.

\subsubsection{Eight EOR Types Based on I-P/C Model}

Similar to Fiedler and Chemers' (1974) approach in constructing the contingent leadership model, we divide EOR into eight types according to the different levels of organizational inducements (I), employee's performance (P) and commitment (C). Table 1 illustrates each type of EOR.

Table 1 EOR Types Based on I-P/C Model

\begin{tabular}{|c|c|c|c|c|c|c|c|c|}
\hline \multirow{3}{*}{$\frac{\text { Inducement }}{\frac{\text { Performance }}{\text { Commitment }}}$} & \multicolumn{4}{|c|}{ High } & \multicolumn{4}{|c|}{ Low } \\
\hline & \multicolumn{2}{|c|}{ High } & \multicolumn{2}{|c|}{ Low } & \multicolumn{2}{|c|}{ High } & \multicolumn{2}{|c|}{ Low } \\
\hline & High & Low & High & Low & High & Low & High & Low \\
\hline
\end{tabular}

We describe the feature of these different types of EOR as below.

Ideal EOR. In this relationship, the organization offers high inducements to employees, and employees reciprocate with high performance and commitment. Both sides pay great attention to the development of other side. In sum, this is a relatively ideal management condition in which the organization has high economic profit and employees have good opportunities of career development.

Transactional EOR. In this kind of EOR, the employer invests high and broad inducements on employees, and employees responds with high performance. However employees are not committed to the employer. They may take the relationship as a transaction, do not intend to stay in the organization for a long time, and probably will quit the job when there is a better choice.

Inefficient EOR. In this type of EOR, inducements offered by the organization are high, while employees are committed but only demonstrate a relatively low level performance. When an organization operates in a stabilized business environment and does not put much pressure on its employees who enjoy generous benefits, this type of EOR will occur. This kind of EOR can be found in some Chinese state-owned enterprises, which enjoy either monopoly market or government subsidy.

Unsustainable EOR. It is an EOR type characterized by high organizational inducements, employees' low performance and low commitment. This kind of relationship is also quite common in some Chinese state-owned enterprises, in which the employees enjoy generous benefits but their performance and commitment is low because of poor management. The organizational inducements are not likely to be sustainable in the long term, unless the organization is protected from market competition. 
Dedicated EOR. The organization offers limited and low inducements to the employee, but the employee reciprocate the organization with high performance and high commitment. A possible reason for such type of EOR is that employees are strongly motivated and devoted to their work due to high intrinsic satisfaction and need for achievement.

Risky EOR. Although the organization offers only low and limited inducements to employees, employees still work hard with high performance. However, their commitment to the organization is low. The possible reason is that employees face tremendous work pressure from the management and have few other work choices. If there are other opportunities, they may leave the organization immediately. This situation is often seen in privately-owned companies.

Burdened EOR. In this relationship, an organization offers low inducements to its employees, which results in low work performance. However, employees are committed to the organization because of job security, close interpersonal relationship, or low competition pressure. This kind of EOR is also common in some Chinese state-owned enterprises.

Harmful EOR. Low organization inducements are provided and therefore employees work with poor performance and low commitment to their organizations. Such employees are frustrated and demoralized with poor benefits and insecure work environment. It often exists in organizations experiencing operational difficulties.

\subsubsection{Effect of EOR Type on Employees' Satisfaction}

Since the above EOR types have different features, employees in which types of EOR can experience higher level of satisfaction? Thibaut and Kelly (1986) suggested that relative satisfaction at social exchange refers to how happy or sad the outcome makes one feel and the satisfaction is relative to people's comparison level $(\mathrm{CL})$ and comparison level of alternative $\left(\mathrm{CL}_{\text {alt }}\right)$.

A person's $C L$ is the threshold above which an outcome seems attractive. For instance, when an employee believes that inducements offered by his/her organization are equal to or larger than his/her contributions to the organization, he/she will be more satisfied (March \& Simon, 1958). Or employees may feel satisfied or unsatisfied after comparing actual benefit gained with benefit expected (London, 1992). $\mathrm{CL}_{\text {alt }}$ is pegged by the best payoffs available outside the current relationship, and is also the worst outcome a person will accept and still stay in a relationship. For example, one may be satisfied with current relationship because of no other choice, and unsatisfied with the current EOR because of opportunity of better exchange with other employers.

According to the above analysis, we propose: 
H3 Employee's satisfaction varies across different types of EOR.

To sum up the above analysis, Fig. 1 presents the conceptual model tested in this study.

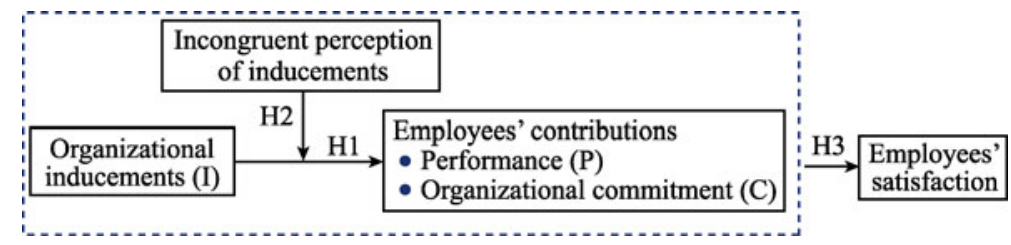

Fig. 1 I-P/C Model of EOR from a Dual Perspective

\section{Method}

A paper-based questionnaire was used to collect data, independently from employees and supervisors. The supervisors provided data on the organizational inducements offered to the sampled subordinates, task performance and organizational citizenship behavior of the subordinate. The subordinates reported their perceived organizational support, and organizational commitment. In order to match data from supervisors and subordinates, we assigned identity codes to the surveys.

\subsection{Sample}

Data for this study were collected from two sources. The first source was MBA students and participants to management training programs. They finished the managers' questionnaire in class, and were requested to deliver the subordinates' questionnaire to a randomly selected subordinate. The subordinate was instructed to mail back the completed questionnaires to researchers. We distributed 1022 questionnaires and 264 were returned, from which 119 matched dyads containing complete data were used for our analyses.

We also collected data from companies that we could access through personal contacts. After getting approval from the top executives of these companies, we administered the survey on site. To identify qualified subjects, we obtained a list of all employees whose corporate tenure was at least half a year, and we randomly selected one or two employees from each unit as well as their immediate supervisors. We then distributed questionnaires to the sampled employees and supervisors, and we collected completed questionnaires from company sites. We distributed 328 questionnaires in this way, and 296 were returned, from which 137 matched dyads containing complete data were used for our analyses. 
Because MBA students and management training participants may be biased in choosing their "star" subordinate into our study, the sample might not be representative of all employees in their units. To rule out the possibility, we compared the employees selected by MBA students and training participants to those selected by ourselves, in terms of their leader-member exchange and task performance. The means are not different significantly between the two groups $(t$ ratio ranges from -0.72 to $1.59, p>0.05$ ), which suggested that the employees were randomly selected by MBA students and management training participants, and that their data can be combined with other data for analyses.

Totally, we obtained a sample of 256 employees and their 204 supervisors with a response rate of $41.5 \%$, among which 143 dyads of supervisor and subordinate were from 22 private companies, 113 dyads from 13 state owned enterprises. Most employee respondents were at junior level (28.3\%) or middle level $(68.9 \%)$. About $70 \%$ of them were male, and $75.8 \%$ of them had worked for present employer for above three years. Among our manager sample, $78.6 \%$ were at the middle level and $21.4 \%$ the top level. Nearly $90 \%$ of them were male, and $64.5 \%$ had tenure of above three years.

\subsection{Measures}

All the variables were measured by previously validated scales except incongruent perception (which was calculated from data reported by supervisors and subordinates). The scales of inducements, OCB, and organizational commitment were developed by sample of Chinese employees, while task performance, perceived organizational support, and satisfaction were developed in western countries. Translation and back-translation process was conducted to make sure the Chinese version of the western scales express the same thing as the English version. CFA analysis was used to confirm the structural validity of the measures. In order to measure the difference between the covariance matrix predicted by the model and the one resulting from the sample data, the following goodness of fit indices were selected: NNFI and CFI with the recommended level of 0.90, RMSEA with the recommended level of 0.1 (Steiger, 1990), and SRMR which is acceptable when lower than 0.08 ( $\mathrm{Hu} \&$ Bentler, 1998).

\subsubsection{Organizational Inducements}

We used the items developed by Wang et al. (2003) in China to measure organizational inducements. Fifteen items measured two dimensions of inducement: developmental inducements (10 items) and economic inducements ( 5 items). The raters were asked to indicate to what degree the company provided higher level of inducements for the subordinate than his or her peers. The 
response scale ranged from 1 representing "much lower than his or her peers" to 7 representing "much higher than his or her peers." A CFA confirmed the two inducements dimensions. The goodness-of-fit indices for the CFA on the inducements dimensions were: RMSEA $=0.11, \mathrm{SRMR}=0.07, \mathrm{NNFI}=0.94$, $\mathrm{CFI}=0.95$. In addition, the alpha coefficients for the two dimensions were 0.85 and 0.92 . Both are acceptable.

\subsubsection{Task Performance}

Items adapted by Tsui et al. (1997) were used to measure task performance. Six items were adopted for the supervisors to assess their subordinates' task performance in terms of quantity, quality, and efficiency. The response scale ranged from 1, "strongly disagree," to 7, "strongly agree," and supervisors indicated the extent to which they agreed that the employee's performance was consistent with the description like "the quality of work is much higher than average." A CFA confirmed a one-factor structure, with RMSEA $=0.2, \mathrm{SRMR}=$ 0.05 , NNFI $=0.91, \mathrm{CFI}=0.95$. The alpha coefficient of this measure was 0.93 . Though the RMSEA exceeded the recommended level of 0.1 , which indicated that some residuals were correlated, as other goodness of fit indices were acceptable, we did not modify the model blindly.

\subsubsection{Organizational Citizenship Behavior}

The scale with 20 items developed by Farh et al. (1997) in China was used to measure five dimensions of OCB: boosterism, altruism, conscientiousness, interpersonal harmony, protecting company resources. Supervisors were asked to assess the extent to which the employee performed these behaviors. A 7-point response scale was used, ranging from 1, "strongly disagree," to 7, "strongly agree." The CFA confirmed the five dimensions. The goodness-of-fit indices for the CFA were: $\mathrm{RMSEA}=0.08, \mathrm{SRMR}=0.04, \mathrm{NNFI}=0.97, \mathrm{CFI}=0.98$. The alpha coefficients for the five dimensions were all in the acceptable range of between 0.87 and 0.92 .

\subsubsection{Organizational Commitment}

We adapted 15 items from Ling, Zhang and Fang (2001) to measure organizational commitment. These items reflect three dimensions: affective commitment, normative commitment and ideal commitment. The raters were required to indicate to the extent they agreed with the descriptions of commitment like "I have a deep affection for the company." The employees in the sample provided data on this measure with a 7-point response scale, ranging 
from 1, "strongly disagree," to 7, "strongly agree." A CFA confirmed the three dimensions. The goodness-of-fit indices for the CFA were: RMSEA $=0.10$, SRMR $=0.06, \mathrm{NNFI}=0.94, \mathrm{CFI}=0.95$, respectively. The alpha coefficients for the three dimensions were all in the acceptable range of between 0.83 and 0.88 .

\subsubsection{Incongruent Perception of Inducements}

Incongruent perception of inducements in the current study was calculated from organizational inducements reported by supervisors and perceived organizational support reported by employees. Although perceptual gaps between supervisors and subordinates are recommended to be operationalized as difference scores either at the item level or the scale level with a same scale (Tetrick, 2004), the authors found that it was difficult for the employees to assess the inducements offered to them, because most employees do not know exactly the inducements offered to their peers, so they cannot be aware of whether the inducements they received is higher or lower than that of their peers. Alternatively, perceived organizational support can express employees' perception of inducements better than direct measurement, for it can be classified as an evaluation-oriented measure of psychological contract fulfillment (Rousseau and Tijoriwala, 1998; Guzzo, Noonan and Elron, 1994).

As economic and developmental inducements are different kinds of social exchange resources according to Foa and Foa (1980), economic inducements are more concrete than developmental ones, and need shorter time to be exchanged. Thus the incongruent perception of economic or developmental inducements in this article was calculated respectively. The computing method was to get squared difference between perceived organizational support reported by employees and economic or developmental inducements reported by supervisors.

Perceived organizational support was measured by nine high loading items adapted from the 17 items developed by Eisenberger, Huntington, Hutchison, and Sowa (1986). The subordinate respondents were asked to assess to what extent they agreed with the descriptions about organizational support. A CFA confirmed a one-factor structure, with RMSEA $=0.10, \mathrm{SRMR}=0.05, \mathrm{NNFI}=0.97$, and $\mathrm{CFI}=0.98$, respectively. The alpha coefficient of this measure was 0.90 .

\subsubsection{Satisfaction}

We used six items from Rice (1991) to measure satisfaction. Employees in the sample were asked to rate to what extent they agreed with the descriptions about their overall satisfaction, such as "to what degree you are satisfied with your current job." The response scale ranged from 1, "strongly disagree," to 7, "strongly agree." A CFA confirmed a one-factor structure, with RMSEA $=0.10$, 
SRMR $=0.04, \mathrm{NNFI}=0.97$, and CFI $=0.98$, respectively. The alpha coefficient of this measure was 0.89 .

\section{Results}

\subsection{Description and Correlation Matrix}

Table 2 shows that the internal consistency reliabilities for all of the multi-item scales were reasonable. Developmental inducements are correlated with employees' task performance, $\mathrm{OCB}$, and organizational commitment to a greater extent than economic inducements. The two types of incongruent perception of inducements are also correlated with each other $(r=0.43)$.

\subsection{Organizational Inducements and Employee Contributions}

We conducted structural equation modeling to test the effect of organizational inducements on employees' contributions. We parceled items of each dimensions of organizational citizenship behavior and organizational commitment to create a manageable number of indicators for such constructs, because LISREL has difficulties fitting models with more than 30 manifest indicators (Bentler and Chou, 1987).

The effects of economic and developmental inducements on employees' contributions were analyzed separately. Results in Fig. 2 show an acceptable fit to the model: $\mathrm{NNFI}=0.94, \mathrm{CFI}=0.95, \mathrm{RMSEA}=0.10$ and $\mathrm{SRMR}=0.07$. These fitness indices meet or exceed recommended cutoff values (Hu and Bentler, 1998; Steiger, 1990).

Results in Fig. 3 also show acceptable fit indices (RMSEA $=0.10$, SRMR $=$ 0.07 , NNFI $=0.95, \mathrm{CFI}=0.95$ ) of the hypothesized model. Fig. 2 and Fig. 3 indicate that both economic and developmental inducements have positive effect on employees' task performance and OCB, but the effect of developmental seemed stronger and only developmental inducements had effect on organizational commitment. So H1 is partially supported.

\subsection{Moderating Effect of Incongruent Perception on Employee Organization Relationship}

Among all the employees in the present sample, $67.2 \%$ of them had "negative gap" with their supervisors in term of incongruent perceptions of developmental inducements, and $40.2 \%$ had "negative gap" with their supervisors in term of incongruent perceptions of economic inducements. The reason may be economic inducements are more concrete than developmental inducements, so they are less likely to be underestimated by sample employees. 


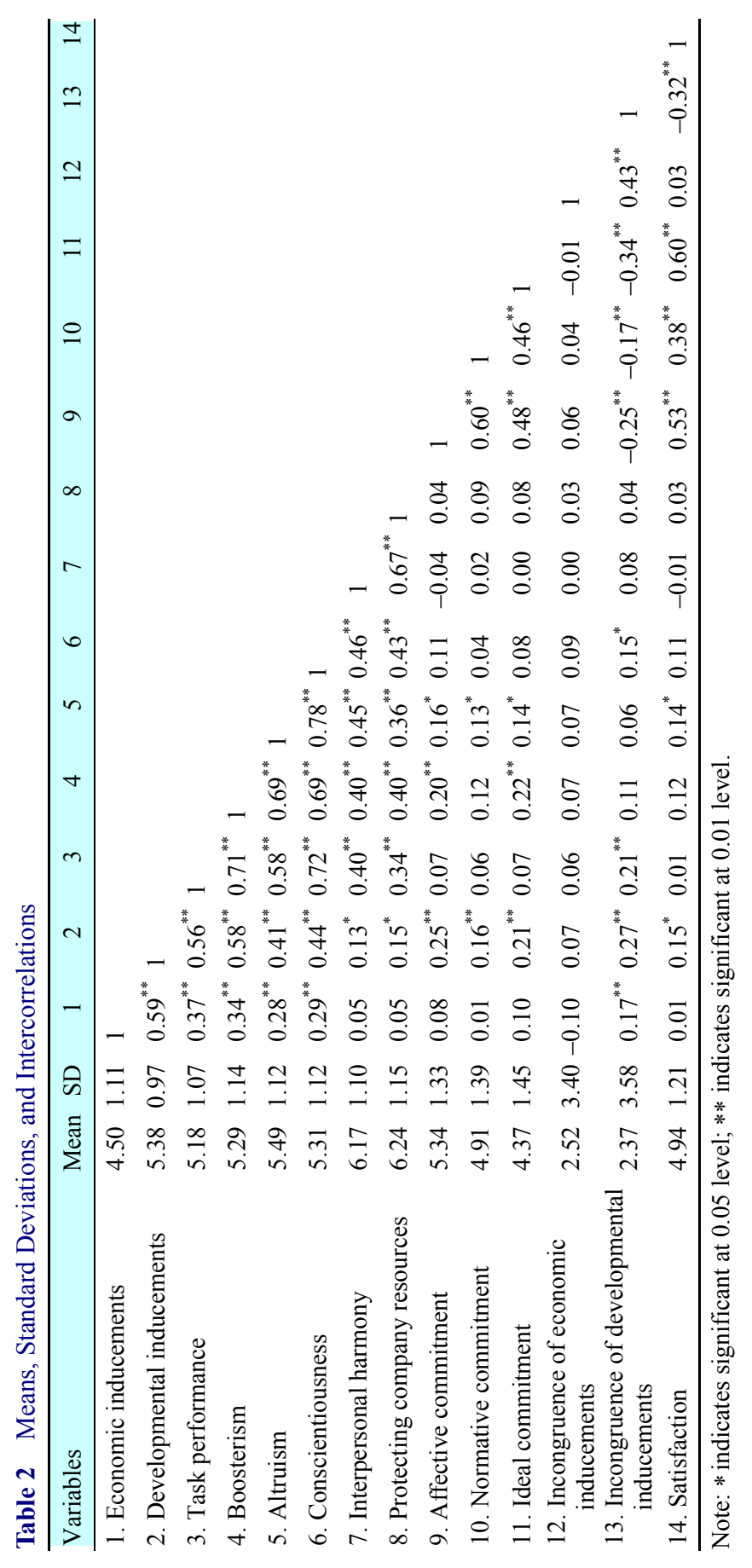




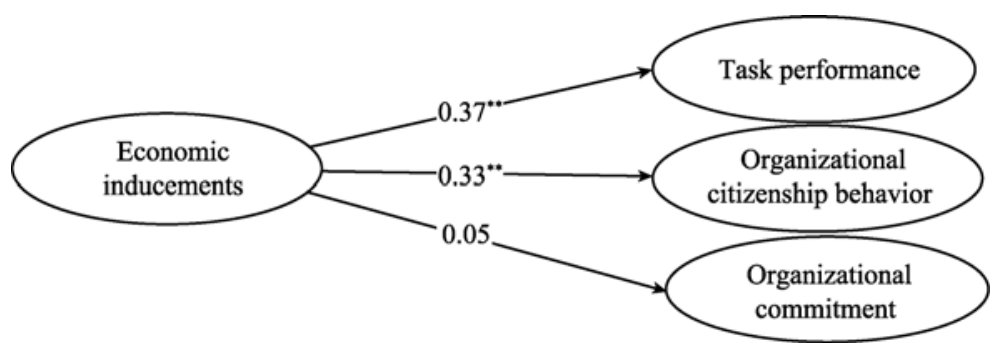

Fig. 2 Effect of Economic Inducements on Employee Contribution Note: ** indicates significant at 0.01 level.

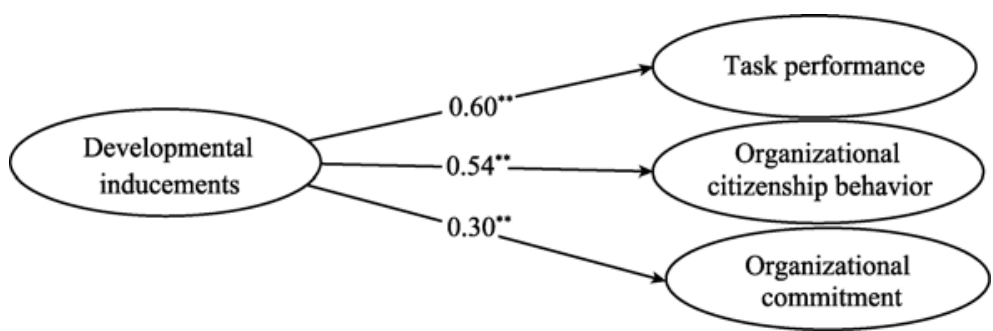

Fig. 3 Effect of Developmental Inducements on Employee Contribution Note: $* *$ indicates significant at 0.01 level.

To test the moderating effect of incongruent perception, we sorted the entire sample in the ascending order of perceptual incongruence of economic inducements, and the first $40 \%$ of the sample (102 respondents) was coded as "economically congruent group," the last $40 \%$ of the employee sample (102 respondents) as "economically incongruent group." Similarly, we produced another two groups: "developmentally congruent group" and "developmentally incongruent group."

Firstly, we compared the relationship of economic inducements and employees' contributions between the "economically congruent group" and "economically incongruent group."

The two models in Fig. 4 and Fig. 5 both have an acceptable goodness-of-fit.

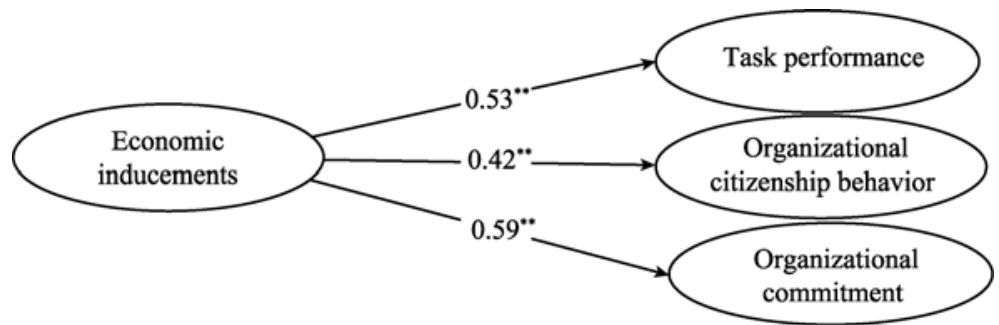

Fig. 4 Economic Inducements and Employee Contribution (the Economically Congruent Group)

Note: $* *$ indicates significant at 0.01 level. 


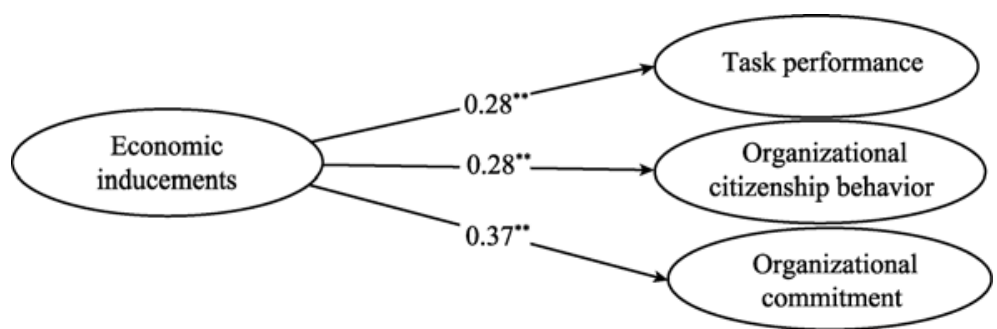

Fig. 5 Economic Inducements and Employee Contribution (the Economically Incongruent Group)

Note: $* *$ indicates significant at 0.01 level.

Goodness-of-fit indices of the model in Fig. 4 are: RMSEA $=0.11$, SRMR $=0.10$, $\mathrm{NNFI}=0.92, \mathrm{CFI}=0.93$; goodness-of-fit indices of the model in Fig. 5 are: RMSEA $=0.10$, SRMR $=0.08, \mathrm{NNFI}=0.92, \mathrm{CFI}=0.93$. After comparing Fig. 4 with Fig. 5, we found that in "economically congruent group" economic inducements were positively correlated with employees' organizational commitment; while they were negatively related in the other group. We also found that the relationship between economic inducements and employees' performance is stronger when there is a smaller perceptual gap.

In order to test that the difference of path coefficients in the two models is statistically significant, three multi-group structure equation models were estimated, as showed in Table 3. All the parameters in the "economically congruent group" and "economically congruent group" were set to be equal in Model 1. Path coefficients and factor loadings were set to be free in Model 2, and all the parameters were set to be free in Model 3. The results of Model 1 do not support that all the parameters are equal $\left(\chi^{2}(339)=953.88, p<0.01\right)$. When more parameters are set to be free, the fit indices improve. The decrease of Chi-square across the three models is statistically significant $(p<0.01)$, which indicates that the difference between path coefficients in Fig. 4 and Fig. 5 is significant.

Table 3 Multi-Sample Structured Equation Model Test (1)

\begin{tabular}{|c|c|c|c|c|c|c|}
\hline Model & $\chi^{2}$ & $\mathrm{df}$ & RMSEA & SRMR & NNFI & CFI \\
\hline Model 1 (all the parameters are equal) & 953.88 & 339 & 0.13 & 0.22 & 0.88 & 0.88 \\
\hline $\begin{array}{l}\text { Model } 2 \text { (free factor loadings and } \\
\text { path coefficients) }\end{array}$ & $\begin{array}{l}807.19 \\
\Delta \chi^{2}=146.69\end{array}$ & $\begin{array}{l}320 \\
\Delta \mathrm{df}=19\end{array}$ & 0.13 & 0.14 & 0.89 & 0.90 \\
\hline Model 3 (free all the parameters) & $\begin{array}{l}700.70 \\
\Delta \chi^{2}=106.69\end{array}$ & $\begin{array}{l}301 \\
\Delta \mathrm{df}=19\end{array}$ & 0.12 & 0.14 & 0.89 & 0.91 \\
\hline
\end{tabular}

Secondly, we compared the effects of developmental inducements on 
employees' contributions between the "developmentally congruent group" and "developmentally incongruent group."

The two models in Fig. 6 and Fig. 7 both have an acceptable goodness-of-fit. Goodness-of-fit indices of the model shown in Fig. 6 are: RMSEA $=0.10$, $\mathrm{SRMR}=0.08, \mathrm{NNFI}=0.96, \mathrm{CFI}=0.96$; Goodness-of-fit indices of the model shown in Fig. 7 are: RMSEA $=0.10$, SRMR $=0.08, \mathrm{NNFI}=0.92, \mathrm{CFI}=0.93$. Comparing Fig. 6 to Fig. 7, we find that in the "developmentally congruent group," developmental inducements are positively correlated with employees' commitment; while they two have no relationship with each other in the "developmentally incongruent group." We also find that when there is a smaller perception gap, developmental inducements have stronger effect on employees' OCB.

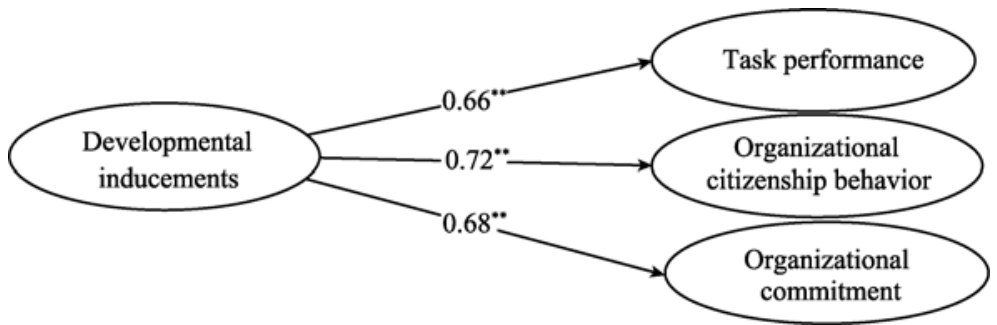

Fig. 6 Developmental Inducements and Employee Contribution (the Developmentally Congruent Group)

Note: $* *$ indicates significant at 0.01 level.

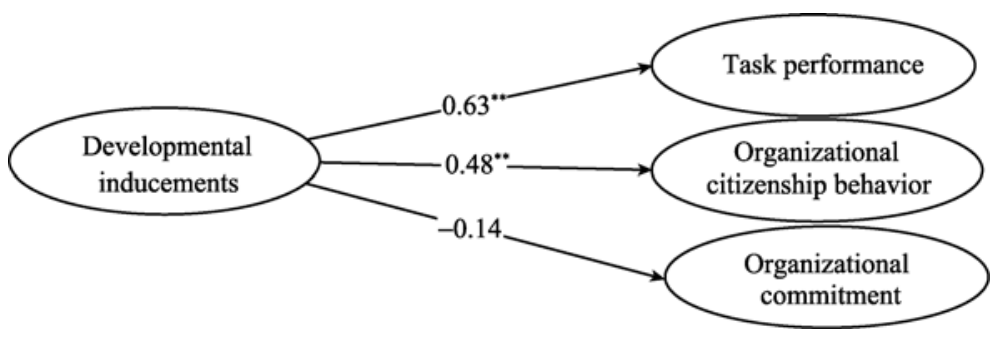

Fig. 7 Developmental Inducements and Employee Contribution (the Developmentally Incongruent Group)

Note: $* *$ indicates significant at 0.01 level.

Similar to the analysis in Table 3, three multi-group structured equation models were estimated to test the significance of coefficient difference between Fig. 6 and Fig. 7. As Table 4 shows, Model 1 does not support that all the parameters are equal $\left(\chi^{2}(549)=1166.46, p<0.01\right)$, When factor loadings and path coefficients are set to be free in Model 2, the fit indices become better than Model 1. The decrease of Chi-square across the three models is statistically 
significant $(p<0.01)$, which indicates that the difference of path coefficients in Fig. 6 and Fig. 7 is significant.

Table 4 Multi-Sample Structured Equation Model Test (2)

\begin{tabular}{lllcccc}
\hline Model & \multicolumn{1}{c}{$\chi^{2}$} & \multicolumn{1}{c}{$\mathrm{df}$} & RMSEA & SRMR & NNFI & CFI \\
\hline Model 1 (all the parameters are equal) & 1166.46 & 549 & 0.11 & 0.16 & 0.93 & 0.93 \\
$\begin{array}{l}\text { Model 2 (free factor loadings and path } 1109.17 \\
\text { coefficients) }\end{array}$ & $\begin{array}{l}525 \\
\chi^{2}=57.29\end{array}$ & $\Delta \mathrm{df}=24$ & 0.11 & 0.11 & 0.93 & 0.94 \\
Model 3 (free all the parameters) & $\begin{array}{l}1051.82 \\
\Delta \chi^{2}=57.35\end{array}$ & $\begin{array}{l}501 \\
\Delta \mathrm{df}=24\end{array}$ & 0.10 & 0.11 & 0.93 & 0.94 \\
\hline
\end{tabular}

According to the above analysis, $\mathrm{H} 2$ is partially supported, that is, incongruent perception of inducements can moderate the relationship between organizational inducements and employees' contributions, especially between organizational inducements and employees' commitment.

\subsection{EOR and Employees' Satisfaction}

Before exploring the effect of EOR on employees' satisfaction, we calculated factor scores of each dimension of organizational inducements, task performance, $\mathrm{OCB}$, and organizational commitment through factor analysis. The factor scores were added up to total scores weighted by the percent of variance extracted. Total scores of task performance and OCB were averaged to obtain total score of performance. We divided the employees sample into high level groups and low level groups according to the mean of total scores of organizational inducement (I), employees' performance $(\mathrm{P})$ and commitment $(\mathrm{C})$, respectively. Then this process yielded eight combinations by the three variables in the I-P/C Model $(2 \times 2 \times 2)$, corresponding to the eight types of different EOR showed in Table 1, and their frequencies are showed in Table 5.

Table 5 Eight Types of Employee Organization Relationship

Name of Ideal Transactional Inefficient Unsustainable Dedicated Risky Burdened Harmful
types

\begin{tabular}{cccccccc} 
types & Ideal & Transactional Inefficient & \multicolumn{1}{c}{ Unsustainable Dedicated Risky } & Burdened Harmful \\
\hline Frequency $25.0 \%$ & $13.7 \%$ & $9.0 \%$ & $4.7 \%$ & $5.5 \%$ & $9.0 \%$ & $16.4 \%$ & $16.8 \%$ \\
\hline
\end{tabular}

Among our samples, there was a high proportion of "ideal" EOR, implying that people intend to keep equivalent EOR because of the function of norm of reciprocity. The "burdened" and "transactional" EOR also hold a relatively high proportion in our sample. This may be explained by different levels of competence across employees because employees' performance usually is 
connected with their competence. Competent employees often have more other choices, so even they get high inducements from the organization and perform well in work; they are still looking forward to better opportunity. Meanwhile, incompetent employees have less other choices, so even they only receive low inducements from the organization, and behave low performance; they still could embrace high commitment to the organization.

Employee satisfaction in each type of EOR is showed in Table 6. The employees in "ideal" and "dedicated" EOR enjoy highest level of satisfaction, second highest with those in "inefficiency" and "burdened" EOR. The employees in "transactional" and "risky" EOR have lowest level of satisfaction.

Table 6 Employees' Satisfaction under Eight Types of EOR

\begin{tabular}{|c|c|c|c|c|c|c|c|c|c|}
\hline \multirow{2}{*}{$\begin{array}{c}\text { Employees' } \\
\text { outcome }\end{array}$} & \multicolumn{8}{|c|}{ Types of EOR } & \multirow{2}{*}{$\begin{array}{c}\text { ANOVA } \\
F\end{array}$} \\
\hline & Ideal 1 & Transactional & Inefficiency & Unsustainable & Dedicated & Risky & Burdened & Harmful & \\
\hline Satisfaction & $5.58^{\mathrm{a}}$ & $4.25^{\mathrm{b}}$ & $5.38^{\mathrm{a}, \mathrm{c}}$ & $4.31^{\mathrm{b}, \mathrm{c}, \mathrm{d}}$ & $5.62^{\mathrm{a}, \mathrm{c}, \mathrm{d}}$ & $4.15^{b}$ & $5.25^{\mathrm{a}, \mathrm{c}, \mathrm{d}}$ & $4.41^{\mathrm{b}, \mathrm{c}}$ & \\
\hline SD & 0.96 & 1.22 & 1.15 & 1.13 & 1.03 & 1.07 & 1.10 & 1.04 & $10.91^{* *}$ \\
\hline Obs. & 64 & 35 & 23 & 12 & 14 & 23 & 42 & 43 & \\
\hline
\end{tabular}

Note: $a, b, c, d$ means that the types with the same superscripts are at the same satisfaction level; ** indicates significant at 0.01 level.

An ANOVA showed that EOR types have effect on employees' satisfaction $\left(F=10.91, p<0.01, R^{2}=0.24\right)$. Levene test supported that the variances of satisfaction in the eight groups were equal $(F=0.59, p>0.05)$. As the numbers of respondents in the eight groups were not equal, Scheffe analysis was employed to compare mean of satisfaction across the eight groups.

As shown in Table 6, means with the same superscript character are not different from each other significantly. Employees in "ideal," "inefficiency," "dedicated," and "burdened" EOR have higher degree of satisfaction than those in other types of EOR significantly. And there is no significant difference across these types of EOR.

To sum up, employees' satisfaction does vary across different types of EOR, which partially supports $\mathrm{H} 3$. On the one hand, employees' satisfaction is relatively high in balanced type of EOR like "ideal," and in type of "inefficiency" characterized by higher inducements and lower contributions. On the other hand, employees' satisfaction can also be relatively high when inducements offered is lower than contributions, like the type of "dedicated" and "burdened."

This phenomenon is probably related to incongruent perception of inducements. Organizational inducements in the present study were reported by supervisors, as they know more about real inducements than their subordinates. But employees make the decision of repayment according to their own 
perception of inducements, and their perception may be higher or lower than that of their supervisors.

Furthermore, from the perspective of $\mathrm{CL}_{\text {alt }}$ mentioned above, employees with high commitment may be satisfied with current unbalanced EOR because they are lack of other better choice.

\section{Discussion}

\subsection{Conclusion and Implication}

The main contribution of this article is the development of I-P/C model reflecting EOR from dual perspectives. This model can be viewed as integration of Rousseau's PC Model and Tsui et al.'s I/C Model. The model contributes to EOR research in a few ways: (1) it explicates the reciprocity of social exchange with considerations of both the contents of the social exchange in employment relationship and the perception incongruence between employees and managers who acts as the agent of organization; (2) it explores the moderating effect of the perception incongruence in the social exchange between two sides; (3) it includes organizational commitment as part of employees' contribution which represents their loyalty to the organization; (4) it shows the resulting effect of this social exchange on employees' feeling which is expressed by their satisfaction.

The first finding of this study is that developmental inducements have stronger effects on employee's contributions than do economic inducements, and economic inducements have no effect on employees' commitment. This seems to be conflict with norm of reciprocity, but this finding is consistent with the adjacent principle suggested by Foa and Foa (1980). According to the principle, social exchange resources are categorized in six types by whether they are concrete or abstract; need long time to complete exchange or short time. The six types of social exchange resources are currency, goods, service (including behavior), information, status, and love. It has been proved that people prefer exchange of adjacent resources with similar characteristics. With regard to exchange resources in EOR, economic inducements are mainly currency, and commitment is some kind of love, so economic inducements offered by organization are difficult to be paid off by employee's commitment. This finding suggests that both norm of reciprocity and adjacent principle function in EOR. Maybe future study can compare the function of the two social exchange principles. This result also confirms hygiene-motivating factor theory (Herzberg, 1968). Economic inducements are similar to hygiene factor, cannot motivate employee's commitment; while developmental inducements are like motivating factor, can generate stronger repayment from employees.

The second finding of this paper is that the moderate effect of the perceptual 
incongruence on EOR is proved, which can partly explain why many companies are puzzled that their "high" inducements can not be paid off. This result is logically consistent with prior findings that perception gap of inducements has negative effect on employees' performance and attitude (Chen et al., 2008; Li and Sun, 2006). Moreover, some researchers find that there also exists gap between supervisors and subordinates' perception of mutual obligations in EOR (Tekleab and Taylor, 2003). The perception of obligation may imply expected exchange benefit, so the perception gap of obligation may lead to perception gap of inducements. Of course, this point needs to be verified in future research.

The third finding of this paper is that employees' satisfaction varies across different EOR types based on I-P/C model. The result implicates that the two kinds of comparison level ( $C L$ and $\mathrm{CL}_{\text {alt }}$ ) have functions in the relationship between EOR types and employees' satisfaction. When evaluating their exchange benefit, employees not only intend to compare organizational inducements with their contributions, but also probably compare the current EOR with alternative other possible EORs.

The above contributions and findings can give helpful suggestions to practitioners. The first is to pay more attention to developmental inducements; the second is to narrow the perceptual gap, the third may be that EOR types can be identified by survey based on I-P/C model and different measures could be adopted correspondingly to manage them.

\subsection{Limitations and Suggestions for Future Research}

The first limitation of this research is the cross-sectional design. Future research would benefit from employing a longitudinal research design to establish the causal relationship. The second limitation is that we only studied the perceptual incongruence of organizational inducement. Future studies can study the perceptual incongruence of employees' contributions. Because employees may overestimate their contributions, any incongruence may also moderate the exchange relationship between the two parties. Lastly, managers are also employees themselves, so their multiple social exchange roles in the organization deserve research attention in future studies of EOR.

Acknowledgements This research project is supported by the National Natural Science Foundation of China (No. 70972107, 70802010). The authors thank Anne S. Tsui, Lois Tetrick, and Hao Zhao for their valuable comments and suggestions.

\section{References}

Al-Waqfi M A, Agarwal N C (2006). Determinants of role orientation and organizational commitment under skill-based pay: A path model. International Journal of Human Resources 
Development and Management, 6(1): 4-21

Barnard C I (1938). The Functions of the Executive. Cambridge: Harvard University Press, $145-157$

Bentler P M, Chou, C P (1987). Practical issues in structural modeling. Sociological Methods \& Research, 16(1): 78-117

Borman W C, Motowidlo S J (1997). Task performance and contextual performance: The meaning for personnel selection research. Human Performance, 10(2): 99-109

Chen Z X, Tsui A S, Zhong L F (2008). Reactions to psychological contract breach: A dual perspective. Journal of Organizational behavior, 29(5): 527-548

Coyle-Shapiro J A M, Kessler I (2002). Exploring reciprocity through the lens of the psychological contract: Employee and employer perspectives. European Journal of Work and Organizational Psychology, 11(1): 69-86

Eisenberger R, Huntington R, Hutchison S, Sowa D (1986). Perceived organizational support. Journal of Applied Psychology, 71(3): 500-507

Farh J L, Earley P C, Lin S C (1997). Impetus for action: A cultural analysis of justice and organizational citizenship behavior in Chinese society. Administrative Science Quarterly, 42(3): 421-444

Farmer S M, Fedor D B (1997). Volunteer participating and turnover intensions: The role of satisfaction, expectations, and organizational support. Academy of Management Proceedings, 97: $380-384$

Fiedler F E, Chemers M M (1974). Leadership and Effective Management. Glenview, Illinois: Scott Foresman Co.

Foa U G, Foa E B (1980). Resource theory: Interpersonal behavior as exchange. In: K J Gergen, M S Greenberg, R H Willis (eds.), Social Exchange: Advances in Theory and Research. New York: Plenum Press, 77-94

Greene C N, Podsakoff P M (1978). Effects of removal of a pay incentive: A field study. Academy of Management Proceedings, 206-210

Gouldner A W (1960). The norm of reciprocity: A preliminary statement. American Sociological Review, 25(2):161-178

Guest D (1998). Is the psychological contract worth taking seriously? Journal of Organizational Behavior, 19(1): 649-664

Guzzo R A, Noonan K A, Elron E (1994). Expatriate managers and the psychological contract. Journal of Applied Psychology, 79(4): 617-626

Herzberg F (1968). One more time: How do you motivate employees? Harvard Business Review, 46(1): 53-62

$\mathrm{Hu}$ L, Bentler P M (1998). Fit indices in covariance structure modeling: Sensitivity to under-parameterized model misspecification. Psychological methods, 3(4): 424-453

Kotter J P (1973). The psychological contract. California Management Review, 15(3): 91-99

Kuvaas B (2006). Work performance affective commitment and work motivation: The roles of pay administration and pay level. Journal of Organizational Behavior, 27(3): 365-385.

Laschinger H K S, Finegan J E (2004). Empowerment, interactional justice, trust and respect: A nursing recruitment and retention strategy. Academy of Management proceedings, $\mathrm{pC} 1-\mathrm{C} 6$

Leana C R (1987). Power relinquishment versus power sharing: Theoretical clarification and empirical comparison of delegation and participation. Journal of Applied Psychology, 72(2): $228-233$

Lester S W, Turnley W H, Bloodgood J M, Bolino M C (2002). Not seeing eye to eye: Differences in supervisor and subordinate perceptions of and attributions for psychological 
contract breach. Journal of Organizational Behavior, 23(1): 39-56

Levinson H, Price C, Mandl H, Solley C (1962). Men, Management, and Mental Health. Cambridge: Harvard University Press

London M (1992). Book review: Job satisfaction: How people feel about their jobs and how it affects their performance. Journal of Management, 18(4): 810-811

March J G, Simon H A (1958). Organizations. New York: Wiley

McFarlin D B, Sweeney P D (1992). Distributive and procedural justice as predictors of satisfaction with personal and organizational outcomes. The Academy of Management Journal, 35(3): 626-637

Meyer J P, Allen N J (1991). A three-component conceptualization of organizational commitment. Human Resource Management Review, 1(1): 61-89

Meyer J P, Stanley D J, Herscovitch L, Topolnytsky L (2002). Affective, continuance, and normative commitment to the organization: A meta-analysis of antecedents, correlates, and consequences. Journal of Vocational Behavior, 61(1): 20-52

Morrison E W, Robinson S L (1997). When employees feel betrayed: A model of how psychological contract violation develops. Academy of Management Review, 22(1): 226-256

Morrison E W, Robinson S L (2004). The employment relationship from two sides: Incongruence in employees' and employers' perceptions of obligations. In: Coyle-Shapiro J, Shore L, Taylor M S, Tetrick L (eds.), The Employment Relationship: Examining Psychological and Contextual Perspectives. Oxford: Oxford University Press, 161-180

Murray B, Gerhart B (1998). Empirical analysis of a skill-based pay program and plant performance outcomes. Academy of Management Journal, 41(1): 68-78

Organ D W (1997). Organizational citizenship behavior: It's construct clean-up time. Human Performance, 10(2):85-97

Parker O, Wright L (2001). The missing link: Pay and employee commitment. Ivey Business Journal, 65(3): 70-73

Porter L W, Pearce J L, Tripoli A M, Lewis K M (1998). Differential perceptions of employer's inducement: Implications for psychological contracts. Journal of Organizational Behavior, 19(1): 769-782

Rice R W, Gentile D A, McFarlin D B (1991). Facet importance and job satisfaction. Journal of Applied Psychology, 76(1): 31-39

Riketta M (2002). Attitudinal organizational commitment and job performance: A meta-analysis. Journal of Organizational Behavior, 23(3): 257-266

Robinson S L, Kraatz M S, Rousseau D M (1994). Changing obligations and the psychological contract: A longitudinal study. Academy of Management Journal, 37(1): 137-152

Roehling M V, Cavanaugh M A, Moynihan L M, Boswell W R (2000). The nature of the new employment relationship: A content analysis of the practitioner and academic literatures. Human Resource Management, 39(4): 305-320

Rousseau D M (1989). Psychological and implied contracts in organizations. Employee Responsibilities and Rights Journal, 2: 121-139

Rousseau D M (1995). Psychological Contracts in Organizations: Understanding Written and Unwritten Agreement. Newbury Park, CA: Sage Publications

Rousseau D M, Tijoriwala S A (1998). Assessing psychological contracts: Issues, alternatives and measures. Journal of Organizational Behavior, 19(1): 679-695

Schein E H (1965). Organizational Psychology. Englewood Cliffs, NJ: Prentice Hall

Steiger J H (1990). Structure model evaluation and modification: An interval estimation approach. Multivariate Behavioral Research, 25(2): 173-180 
Tekleab A G, Taylor M S (2003). Aren't there two parties in an employment relationship? Antecedents and consequences of organization-employee agreement on contract obligations and violations. Journal of Organizational Behavior, 24(5): 585-608

Tetrick L E (2004). Understanding the employment relationship: Implications for measurement and research design. In: Coyle-Shapiro J, Shore L, Taylor M S, Tetrick L (eds.), The Employment Relationship: Examining Psychological and Contextual Perspectives. Oxford: Oxford University Press, 312-331

Tetrick L E, Hu X X, Shore L M (2008). Social exchange theory: Understanding organizational commitment and the employment exchange relationship. The 2008 Meeting of International Association of Chinese Management Research, June 16-22nd, Guangzhou, China

Thibaut J W, Kelley H H (1986). The Social Psychology of Groups. New Brunswick, NY: Transaction Publishers

Tsui A S, Pearce J L, Porter L W, Hite J P (1995). Choice of employee-organization relationship: Influence of external and internal organizational factors, In: Ferris G R (ed.), Research in Personnel and Human Resource Management. Greenwich, CT: JAI Pres, $117-151$

Tsui A S, Pearce J L, Porter L W, Tripoli A M (1997). Alternative approaches to the employee-organization relationship: Does inducement in employees pay off? Academy of Management Journal, 40(5): 1089-1121

Wang D X, Tsui A S, Zhang Y C, Ma L (2003). Employment relationship and firm performance: Evidence from an emerging economy. Journal of Organizational Behavior, 24(5): 511-535

Wayne S J, Shore L M, Bommer W H, Tetrick L E (2002). The role of fair treatment and rewards in perceptions of organizational support and leader member exchange. Journal of Applied Psychology, 87(3): 590-598

Whitener E M, Brodt S E, Korsgaard M A, Werner J M (1998). Managers as initiators of trust: An exchange relationship framework understanding managerial trustworthy behavior. Academy of Management Review, 23(3): 513-530

李原, 孙健敏 (Li Yuan, Sun Jianmin) (2006). 雇用关系中的心理契约: 从组织与员工双重 视角下考察契约中 “组织责任” 的认知差异 (Psychological contract in employment relationship: Perceptual discrepancy of organizational responsibility for dual perspectives of organization and employee). 管理世界, (11): 101-110

凌文轻, 张治灿, 方俐洛 (Ling Wenquan, Zhang Zhican, Fang Liluo) (2001). 中国职工组 织承诺研究 (A study of the organizational commitment of Chinese employees). 中国社会 科学, (2): 90-102

龙立荣, 方俐洛, 凌文辁 (Long Lirong, Fang Liluo, Ling Wenquan) (2002). 组织职业生涯 管理及效果的实证研究 (Organizational career management and its effects on employees' behavior: An empirical study on Chinese enterprises). 管理科学学报, 5(4): 61-67

吴继红, 陈维政 (Wu Jihong, Chen Weizheng) (2010). 领导一成员关系对组织与员工间社 会交换的调节作用研究 (Moderating effect of leader-member exchange on the exchange between employee and organization). 管理学报, 7(3): 363-372 